\title{
Decreased fibrinolytic activity in juvenile chronic arthritis
}

\author{
Luciana Mussoni, Giuseppe Pintucci, Geremia Romano, Fabrizio De Benedetti, \\ Margherita Massa, Alberto Martini
}

\begin{abstract}
The basal fibrinolytic activity in 17 children with active juvenile chronic arthritis (JCA) was investigated. It was found that patients with JCA, and particularly those with the systemic form, show decreased plasma fibrinolytic activity and a marked increase in plasminogen activator inhibitor. Additionally, it was found that patients with systemic JCA, but not those with the polyarticular or pauciarticular form, have increased circulating levels of tissue-type plasminogen activator, an endothelial cell protein, suggesting possible endothelial cell participation in systemic JCA.
\end{abstract}

Juvenile chronic arthritis (JCA) is a heterogeneous condition divided, on clinical grounds, into different subtypes: systemic, polyarticular, and pauciarticular. ${ }^{12}$ The systemic form is characterised by extra-articular manifestations, including high spiking fever, rash, lymphadenopathy, hepatosplenomegaly, serositis, haematological abnormalities such as anaemia, neutrophilia, and thrombocytosis, and marked increase of acute phase proteins. In some of these patients coagulopathy resembling disseminated intravascular coagulation may occur and be accompanied by severe hepatic and neurological manifestations and peripheral thrombosis. ${ }^{3-5}$ A previous study reported that subclinical activation of intravascular coagulation is common in systemic JCA, whereas it is not present in rheumatoid factor negative polyarticular JCA. ${ }^{5}$

In this study we investigated the fibrinolytic system-an enzyme system composed of plasminogen activators (PAs) and inhibitors ${ }^{6}{ }^{7}-$ in patients with active JCA. Plasminogen, the key protein of the fibrinolytic system, circulates in plasma as a zymogen and is converted by PAs into the active enzyme plasmin, a non-specific serine proteinase. From a physiological point of view the tissue-PA (t-PA) is the most important activator of plasminogen and its action is regulated by a rapidly acting inhibitor-the plasminogen activator inhibitor 1 (PAI-1). Whereas t-PA is synthesised and released by endothelial cells, PAI-1 is produced not only by endothelial cells but also by hepatocytes and platelets. An imbalance between activators and antiactivators has often been reported in association with thrombotic episodes such as deep venous thrombosis. ${ }^{89}$ In this study we found that patients with JCA, and particularly those with the systemic form, had reduced plasma fibrinolytic activity, and that patients with systemic JCA had increased circulating levels of $t$-PA.

\section{Patients and methods}

PATIENTS

Seventeen patients (five male, 12 female) with JCA were studied. All fulfilled the criteria for a diagnosis of $\mathrm{JCA}^{1}$ and were classified in different groups dependent on type of onset according to the criteria proposed by the juvenile rheumatoid arthritis criteria subcommittee of the American Rheumatism Association. ${ }^{1}$ Patients who were HLA-B27 or rheumatoid factor positive were excluded from the study. Eight patients presented a systemic form, six a pauciarticular, and three a polyarticular form. Patients were studied during the active phase of their disease, which was defined by evidence of synovitis at examination; none of these patients had clinical signs of disseminated intravascular coagulation or peripheral thrombosis. Table 1 summarises some of the clinical and laboratory data of these patients with JCA. Thirteen normal healthy children matched for age and sex served as controls. For all the children tested extra blood was obtained at time of routine venepuncture with their parents' permission.

Blood, collected by clean venepuncture, was anticoagulated $(1 / 10)$ with $0 \cdot 11 \mathrm{M}$ trisodium citrate dihydrate and kept in ice until plasma separation. Platelet poor plasma, obtained by centrifugation $\left(20\right.$ minutes, $3000 \mathrm{rpm}$ at $4^{\circ} \mathrm{C}$ ), was stored in small aliquots at $-80^{\circ} \mathrm{C}$ until tested. Blood samples were collected from controls and patients on the same occasions.

\section{FIBRINOLYTIC ASSAY}

Fibrinolytic activity was measured as the lytic activity of the euglobulin fraction on a fibrin film. ${ }^{10}$

\section{Euglobulin fraction}

Plasma, rapidly thawed at $37^{\circ} \mathrm{C}$, was diluted $(1 / 10)$ with cold distilled water and then acidified at $\mathrm{pH} 5.9$ with acetic acid $(0.25 \% \mathrm{v} / \mathrm{v})$. After 30 minutes on ice, samples were centrifuged at $4^{\circ} \mathrm{C}$ to precipitate the euglobulin fraction.

\section{Euglobulin lysis area}

The precipitate was dissolved in the original plasma volume with EDTA-gelatin barbital buffer $(\mathrm{pH} \mathrm{7.9)}$ and a $30 \mu \mathrm{l}$ sample was placed on top of a fibrin film prepared as previously described. ${ }^{10}$ After 18 hours' incubation at $37^{\circ} \mathrm{C}$ 
Table 1 Clinical and laboratory data of the patients with systemic, polyarticular, and pauciarticular juvenile chronic arthritis (fCA). Where appropriate, data are presented as means $(S D)$

\begin{tabular}{lccc}
\hline Data & Systemic $\mathcal{F C A}$ & Polyarticular $\mathcal{F C A}$ & Pauciarticular $\mathcal{F C A}$ \\
\hline Number & 8 & 3 & 6 \\
Age (years) & $6 \cdot 1(4 \cdot 3)$ & $11 \cdot 3(5 \cdot 0)$ & $5 \cdot 3(4 \cdot 1)$ \\
Disease duration (months) & $32 \cdot 1(34 \cdot 3)$ & $74 \cdot 3(61 \cdot 2)$ & $38 \cdot 0(40 \cdot 3)$ \\
Men/women & $3 / 5(39 \cdot 2)$ & $1 / 2$ & $1 / 5$ \\
ESR* (mm/h) & $94 \cdot 7(26 \cdot 0(12 \cdot 7)$ & $39 \cdot 3(17 \cdot 4)$ \\
Platelet count (x109/1) & $591(262)$ & $551(147)$ & $407(147)$ \\
Treatment (No receiving) & 1 & 1 & 1 \\
None & 6 & 1 & 5 \\
NSAID* & 0 & 1 & 0 \\
NSAID+auranofin & 1 & 0 & 0
\end{tabular}

${ }^{*}$ ESR = erythrocyte sedimentation rate; NSAID=non-steroidal anti-inflammatory drug. The group of NSAIDs included naproxen and indomethacin.

on a levelling table the fibrin film was coloured with $0 \cdot 1 \%$ amidoSchwarz solution and the diameter of the circular lysis zones measured. The lytic activity was expressed as the mean area $\left(\mathrm{mm}^{2}\right)$ of samples assayed in triplicate on different plates.

Tissue-type plasminogen activator ( $t-P A)$ antigen The plasma concentration of $t-P A$ related antigen was measured by a double antibody sandwich enzyme linked immunosorbent assay (ELISA). Ninety six well microplates (Nunc, Denmark) were coated with goat anti-t-PA IgG (Bio Pools, Umea, Sweden), and the antigen was detected with a rabbit anti-t-PA antiserum prepared in our laboratory ${ }^{11}$ and a peroxidase labelled antirabbit IgG (BioRad Labs, Richmond, USA). The amounts of both free and complexed antigen were calculated by extrapolation from a dose-response curve of pure t-PA as reference protein (Bio Pools, Umea, Sweden).

Plasminogen activator inhibitor (PAI) activity Plasma ability to inhibit plasmin formation induced by t-PA was measured with a plasmin sensitive chromogenic substrate in a microassay system. $^{10}$ Briefly, diluted plasma $(1 / 10)$ was incubated for 10 minutes with different concen-

Table 2 Fibrinolytic indices in patients with juvenile chronic arthritis. Data are presented as means (SD)

\begin{tabular}{lccl}
\hline Variables & Controls & Patients & $p$ Value \\
\hline ELA* $^{*}\left(\mathrm{~mm}^{2}\right)$ & $166 \cdot 0(52 \cdot 3)$ & $90 \cdot 7(68 \cdot 1)$ & 0.003 \\
t-PA* antigen (ng/ml) & $6 \cdot 7(3 \cdot 4)$ & $8.9(4 \cdot 2)$ & NS \\
PAI $^{*}$ activity (IU/ml) & $6 \cdot 1(3 \cdot 7)$ & $24 \cdot 7(12 \cdot 0)$ & 0.009 \\
PAI-1 antigen (ng/ml) & $8.5(4 \cdot 7)$ & $38.9(28 \cdot 2)$ & 0.0001
\end{tabular}

*ELA=euglobulin lysis area; t-PA=tissue-type plasminogen activator; $\mathbf{P A I}=$ plasminogen activator inhibitor.

Table 3 Fibrinolytic indices in patients with systemic juvenile chronic arthritis $(\mathcal{F C A})$ and in those with polyarticular or pauciarticular $\mathcal{F C A}$. Data are presented as means $(S D)$

\begin{tabular}{|c|c|c|c|}
\hline Variables* & $\begin{array}{l}\text { Controls } \\
(n=13)\end{array}$ & $\begin{array}{l}\text { Systemic } \mathcal{Y} C A \\
(n=8)\end{array}$ & $\begin{array}{l}\text { Poly+pauci } \mathcal{Y} C A \\
(n=9)\end{array}$ \\
\hline ELA $\left(\mathrm{mm}^{2}\right)$ & $166 \cdot 0(52 \cdot 3)$ & \multirow{4}{*}{$\begin{array}{l}75 \cdot 2(80 \cdot 6) \\
(p=0 \cdot 001) \\
11 \cdot 2(4 \cdot 5) \\
(p=0 \cdot 023) \\
27 \cdot 6(14 \cdot 6) \\
(p=0 \cdot 038) \\
48 \cdot 0(22 \cdot 7) \\
(p=0.00019)\end{array}$} & \multirow{4}{*}{$\begin{array}{l}104.5(56.2) \\
(p=0.035) \\
6.9(2.7) \\
(N S) \\
22.2(9.9) \\
(p=0.021) \\
28.5(31.9) \\
(p=0.011)\end{array}$} \\
\hline t-PA antigen (ng/ml) & $6.7(3.4)$ & & \\
\hline PAI activity (IU/ml) & $6 \cdot 1(3 \cdot 7)$ & & \\
\hline PAI-1 antigen (ng/ml) & $8 \cdot 5(4 \cdot 7)$ & & \\
\hline
\end{tabular}

*For abbreviations see table 2 . trations $(6-8-10 \mathrm{IU} / \mathrm{ml})$ of standard t-PA (International reference preparation 83/517). The residual t-PA activity was measured in microtitre plates containing $30 \mu \mathrm{g} \mathrm{CNBr}$ digested fibrinogen, 0.2 CTA (Committee on Thrombolytic Agents) $\mathrm{U} / \mathrm{ml}$ human plasminogen (Behring-Werke, Marburg, West Germany), and $0.33 \mathrm{mM}$ chromogenic substrate S-2251 (Kabi Diagnostica, Stockholm, Sweden). The optical density was read at $405 \mathrm{~nm}$ after two hours' incubation at $37^{\circ} \mathrm{C}$ and the amount of $\mathrm{t}$ PA inhibited by plasma samples was calculated from a dose-response curve to t-PA and expressed as IU/ml.

\section{PAI-1 antigen}

The PAI-1 antigen was detected with a commercially available enzyme immunoassay kit (Monozyme, Charlottenlund, Denmark). The ELISA used two different monoclonal antibodies and allowed the detection of total PAI-1, both free and complexed with t-PA.

\section{STATISTICAL ANALYSIS}

The $p$ value was calculated using the Wilcoxon test for unpaired samples. All values are given as means (SD). A p>0.05 was considered not significant.

\section{Results}

Table 2 shows the value of fibrinolytic indices in patients with JCA as compared with those for normal age controls matched for age. The fibrinolytic activity, evaluated by the euglobulin lysis area, was significantly lower in patients than in controls. This decreased activity was accompanied by a significant increase in PAI activity and PAI-1 antigen concentration. The tPA antigen concentrations were higher in the group of patients, but the difference from the controls was not significant.

When patients with JCA were divided into groups according to type of onset, both the systemic and the polyarticular-pauciarticular groups showed a significant decrease in the fibrinolytic activity and a significant increase in PAI activity and PAI-1 antigen concentrations (table 3). The most pronounced differences from controls were found in the patients with systemic JCA, who, additionally, had significantly raised t-PA antigen concentrations (table 3 ). In the polyarticular-pauciarticular group, on the other hand, t-PA concentrations were comparable with those of controls.

No correlation was found between fibrinolytic indices and platelet count, fibrinogen concentrations, or erythrocyte sedimentation rate. No significant differences were noted when patients were divided according to treatment.

\section{Discussion}

Patients with systemic JCA may have a coagulopathy resembling disseminated intravascular coagulation accompanied by hepatic and neurological impairment and sometimes by signs of peripheral thrombosis. ${ }^{3-5}$ Scott et al suggested 
that subclinical activation of intravascular coagulation is common in systemic but not in polyarticular JCA. $^{5}$ Our study shows that patients with active JCA have significant subclinical alterations of the fibrinolytic systemnamely, (a) a decrease in the overall fibrinolytic activity as measured by euglobulin lysis area test; $(b)$ an increase in PAI activity and PAI-1 antigen concentration. When patients were divided according to type of onset these changes were more evident in those with systemic JCA, who, in addition, had a significant increase of $t-$ PA antigen concentrations.

Most of our patients were given non-steroidal anti-inflammatory drugs and therefore cyclooxygenase inhibition may play a part in the reduction of fibrinolytic activity. The effect of high dose aspirin on the fibrinolytic system is controversial and depends on the experimental procedure and the assay used. ${ }^{12} 13$ In our patients it seems unlikely that fibrinolytic activity was reduced by non-steroidal antiinflammatory drug treatment because $(a)$ the plasma fibrinolytic activity was measured in basal conditions - that is, not after venous occlusion, and such an assay is not affected by aspirin treatment ${ }^{12}$; $(b)$ the group of patients with systemic JCA had a much greater decrease in fibrinolytic activity than the poly-pauciarticular group, though all patients were treated with equivalent doses of these drugs.

Scott $e$ al suggested that vasculitis may be the underlying pathophysiological mechanism in systemic JCA. ${ }^{5}$ They found that factor VIII related antigen, an endothelial cell protein, ${ }^{14}$ is increased in systemic but not in polyarticular JCA and suggested that this might depend upon endothelial damage secondary to vasculitis. The raised concentrations of circulating t-PA, another endothelial cell protein, found in systemic JCA but not in the other subtypes, may also support the presence of endothelial protein release secondary to cell damage. These increased concentrations of t-PA, which can induce plasmin formation, were associated with a marked increase in PAI activity, resulting in an overall significant reduction of fibrinolysis. Whether the increase in total PAI-1 antigen is due also to endothelial cell damage remains to be established; PAI-1, indeed, is produced not only by endothelial cells, but also by hepatocytes and platelets, and it is not known which cell type is the major source of this protein in vivo. ${ }^{15}$

Because JCA is characterised by the presence of an inflammatory response, which is more marked in systemic JCA than in the other forms, decreased fibrinolysis may be a consequence of the inflammatory process. It has been shown that cytokines, such as interleukin-1 and tumour necrosis factor, stimulate the in vitro production and release of PAI-1 from endothelial cells and hepatocytes ${ }^{16}{ }^{17}$; moreover, in vivo injection in experimental animals of either interleukin-1 or tumour necrosis factor produces a marked increase in plasma PAI activity. ${ }^{15}$ As both interleukin-1 and tumour necrosis factor act as endogenous pyrogens, induce neutrophilia, and stimulate hepatocytes to produce acute phase reactants, ${ }^{18} 19$ participation of these cytokines in the pathogenesis of systemic JCA seems probable. Moreover, significant spontaneous interleukin-1 production by peripheral blood monocytes has been noted in patients with active JCA or with the systemic form, suggesting that monocyte activation takes place in vivo. ${ }^{20}$ Therefore, it is conceivable that increased circulating concentrations of PAI might depend on release of cytokines.

In conclusion, we have shown that patients with active JCA, and particularly those with the systemic form, show decreased fibrinolytic activity and increased PAI antigen concentration and activity. These changes might be a consequence of the inflammatory process and may help to explain the possible occurrence of severe thrombosis in patients with systemic JCA and disseminated intravascular coagulation. Additionally, we have shown that patients with systemic JCA have increased circulating concentrations of t-PA, thus supporting the hypothesis that endothelial cells play a part in systemic JCA.

Partially supported by Regione Lombardia and IRCCS Policlinico $S$ Matteo. G Pintucci and G Romano are recipients of fellowships from the 'Cassa per il Mezzogiorno'.

1 Brewer E J, Bass J, Baum J, et al. Current proposed revision of JRA criteria. Arthritis R hevom 1977; 20 (suppl 2): 195-9. of JRA criteria. Arthritis Rheum 1977; 20 (suppl 2): 195-9.
Ansell B M. Rheumatic disorders in childhood. London: Butterworth, 1980

3 Silverman E D, Miller III J J, Bernstein B, Shafai T. Consumption coagulopathy associated with systemic juvenile rheumatoid arthritis. I Pediat 1983; 103: 872-6.

4 Hadchouel M, Prieur A-M, Griscelli C. Acute hemorrhagic, hepatic, and neurologic manifestations in juvenile rheumatoid arthritis: possible relationship to drugs or infections. f Pediair 1985; 106: 561-6.

5 Scott J P, Gerber P, Maryjowski M C, Pachman L M. Evidence for intravascular coagulation in systemic onset, but not polyarticular, juvenile rheumatoid arthritis. Arthritis Rhewom 1985; 28: 256-61.

6 Sprengers E D, Kluft C. Plasminogen activators inhibitors. Blood 1987; 69: 381-7.

7 Collen D. On the regulation and control of fibrinolysis. Thromb Haemost 1980; 43: 77-85.

8 Nilsson I M, Ljungner $H$, Tengborg $L$. Two different mechanisms in patients with venous thrombosis and defective fibrinolysis: low concentration of plasminogen activator inhibitor. Br Med $\mathcal{f} 1985$; 290: $1453-4$.

9 Juhan-Vaguel I, Valadier J, Alessi M C, et al. Deficient t-PA release and elevated PA inhibitor levels in patients with spontaneous or recurrent venous deep thrombosis. Thromb Haemost 1987; 57: 67-72.

10 de Gaetano G, Carriero M R, Cerletti C, Mussoni L. Low dose aspirin does not prevent fibrinolytic response to dose aspirin does not prevent fibrinolytic response to
venous occlusion. Biochem Pharmacol 1986; 35: 3147-50.

11 Guarini A, Mussoni L, Gugliotta L, et al. Depressed fibrinolysis in patients with acute leuksemia. $B r f$ Haematol 1987; 66: 327-30

12 Moroz L A. Increased blood fibrinolytic activity after aspirin ingestion. N Engl f Med 1977; 2\%: 525-9.

13 Bertelé V, Mussoni L, del Rosso G, et al. Defective fibrinolytic response in atherosclerotic patients. Effect of iloprost and its possible mechanism of action. Thromb Haemost 1988; 60: 141-4.

14 Wagner D D, Olmsted J B, Marder V J. Immunolocalization of von Willebrand protein in Weibel-Palade bodies of human endothelial cells. $\mathcal{f}$ Cell Biol 1982; 95 : 355-60.

15 Kruithof E K O. Plasminogen activator inhibitor type 1: biochemical, biological and clinical aspects. Fibrinolysis 1988; 2 (suppl 2): $59-70$.

16 Gramse M, Breviario F, Pintucci G, et al. Enhancement by interleukin 1 (IL-1) of plasminogen activator inhibitor interleukin 1 (IL-1) of plasminogen activator inhibitor Biophys Res Comman 1986; 139: 720-7.

17 Schleef R R, Bevilacqua M P, Sawdey M, Gimbrone M A Jr, Loskutoff D J. Cytokine activation of vascular endothelium: effects on tissue plasminogen activator and type I plasminogen activator inhibitor. F Biol Chem 1988; 263: 5797-803.

18 Oppenheim J J, Kovacs E J, Matsushima K, et al. There is more than one interleukin 1. Immunology Today 1986; 7: 45-55.

9 Beutler B, Cerami A. Cachectin: more than a tumor necrosis factor. N Engl Y Med 1987; 316: 379-85.

20 Martini A, Ravelli A, Notarangelo L D, et al. Enhanced interleukin 1 and decreased interleukin 2 production in juvenile arthritis. I Rheumatol 1986; 13: 598-603. 